\title{
Períodos e temperaturas de pré-resfriamento na germinação de sementes de Leonotis nepetaefolia
}

\author{
Periods and pre-cooling temperatures on Leonotis nepetaefolia \\ seeds germination
}

\author{
Andréia Cristina Silva ${ }^{1}$ Eduardo Fontes Araújoº \\ Francisco Affonso Ferreira ${ }^{2}$
}

\begin{abstract}
Com o objetivo de estudar condições favoráveis durante a germinação das sementes de L. nepetaefolia, foi conduzido um experimento utilizando temperaturas de $5^{\circ} \mathrm{C}$ e $10^{\circ} \mathrm{C}$ por períodos de 7 e 14 dias, durante a embebição. Após estes períodos, as sementes foram submetidas a regimes de temperatura contínua $\left(20^{\circ} \mathrm{C}\right)$ ou alternada $\left(20^{\circ} \mathrm{C}\right.$ noite $-30^{\circ} \mathrm{C}$ dia). Adicionalmente foram adotadas duas testemunhas sem pré-resfriamento $\left(20^{\circ} \mathrm{C}\right.$ e $\left.20^{\circ} \mathrm{C}-30^{\circ} \mathrm{C}\right)$. As sementes submetidas ao pré-resfriamento $e$ as testemunhas não germinaram em temperatura contínua de $20^{\circ} \mathrm{C}$. O tratamento pré-resfriado a $10^{\circ} \mathrm{C}$ por 14 dias promoveu maior uniformidade, porcentagem de germinação $(45 \%)$ e índice de velocidade de germinação de Leonotis nepetaefolia comparado à testemunha.
\end{abstract}

Palavras-chave: cordão-de-frade, qualidade fisiológica indice de velocidade de germinação.

\section{ABSTRACT}

The objective of this work was to study beneficial conditions during L. nepetaefolia seeds germination an assay was carried out to study pre-cooling temperatures of $5^{\circ} \mathrm{C}$ and $10^{\circ} \mathrm{C}$ for periods of 7 and 14 days, during seeds soaking. After these periods, the seeds were submitted to continuous $\left(20^{\circ} \mathrm{C}\right)$ or alternate $\left(20^{\circ} \mathrm{C}\right.$ night $-30^{\circ} \mathrm{C}$ day) temperatures. Additionally two controls were studied $\left(20^{\circ} \mathrm{C}\right.$ e $\left.20^{\circ} \mathrm{C}-30^{\circ} \mathrm{C}\right)$ without precooling. The experimental design was completely randomized, with four replications. Seeds submitted to pre-cooling, as well as the controls did not germinate in continuous temperature of $20^{\circ} \mathrm{C}$. The seeds submitted to pre-cooling of $10^{\circ} \mathrm{C}$ for 14 days provided greater uniformity, final germination percentages (45\%) and germination speed index compared to that the control.

Key words: Lion's ear, physiology quality, germination speed index.
Leonotis nepetaefolia, conhecida vulgarmente como cordão-de-frade, é uma planta originária da África tropical, sendo vastamente distribuída nas regiões tropicais e subtropicais da África, Ásia e América. No Brasil, apesar de freqüente, ocorre raramente no extremo Sul (KISSMANN \& GROTH, 2000). Pertence à família Labiatae, é anual, herbácea ou subarbustiva ( 80 a $160 \mathrm{~cm}$ de altura), aromática, apresenta caule quadrangulado e propagase por sementes (LORENZI, 1991).

Tem sido observada em áreas cultivadas com milho, principalmente em sistema de plantio direto, produzindo sementes inclusive no período de entressafra (TOMAZ et al., 2004). A espécie apresenta dormência primária, após a maturação dos frutos (KISSMANN \& GROTH, 2000) o que contribui para incrementar o banco de sementes do solo.

Apesar dos prejuízos ocasionados às espécies cultivadas, $\boldsymbol{L}$. nepetaefolia contém princípios com propriedades terapêuticas (LORENZI, 1991). Informações sobre as condições necessárias para germinação da espécie são imprescindíveis para permitir a produção tecnificada de plantas em fase de domesticação, o que facilitaria o estudo controlado da produção de seus princípios ativos (BROWN JR., 1988).

O trabalho teve como objetivo avaliar o efeito do pré-resfriamento de sementes de $\boldsymbol{L}$. nepetaefolia, em diferentes intervalos e temperaturas, associados à temperatura contínua e alternada após o resfriamento, na germinação da espécie.

\footnotetext{
'Agência Paulista de Tecnologia dos Agronegócios (APTA), Pólo Regional da Alta Sorocabana, CP 298, 19001-970, Presidente

Prudente, SP, Brasil. E-mail: andreiacs@aptaregional.sp.gov.br. Autor para correspondência.

${ }^{2}$ Departamento de Fitotecnia, Universidade Federal de Viçosa, UFV, Viçosa, MG, Brasil.
} 
O experimento, realizado em laboratório, utilizou sementes de $\boldsymbol{L}$. nepetaefolia, provenientes de plantas infestantes existentes em área previamente cultivada com milho sob plantio direto. O lote de sementes foi coletado de glomérulos distribuídos na planta, homogeneizado e submetido à retirada de impurezas. As sementes foram armazenadas durante 9 meses, em ambiente de laboratório, desprovido do controle de temperatura. TOMAZ et al. (2004) relatam aumento na taxa de germinação da espécie com o aumento do período entre a coleta das sementes e a semeadura.

Foram avaliados dez tratamentos, os quais constaram de duas temperaturas de embebição das sementes $\left(5^{\circ} \mathrm{C}\right.$ e $\left.10^{\circ} \mathrm{C}\right)$ por períodos de 7 ou 14 dias na ausência de luz, em câmaras de germinação tipo BOD. Após os períodos de pré-resfriamento, as sementes foram submetidas a dois regimes de temperatura para germinação: contínua $\left(20^{\circ} \mathrm{C}\right)$ ou alternada $\left(20^{\circ} \mathrm{C}\right.$ noturna por 14 horas e $30^{\circ} \mathrm{C}$ diurna por 10 horas), na presença de luz.

As avaliações de germinação foram feitas diariamente, por um período de 46 dias contados a partir da disposição das sementes em temperatura definitiva. A partir dessas informações foram calculados a porcentagem de germinação final (BRASIL, 1992), o índice de velocidade de germinação (MAGUIRE,1962), a germinação acumulada no tempo e os fluxos de germinação a intervalos de 48 horas.

$\mathrm{O}$ delineamento experimental utilizado foi o inteiramente ao acaso, com quatro repetições. Os dados foram submetidos à análise de variância, sendo as médias da germinação final comparadas pelo teste de Tukey a 5\% de probabilidade. Foram ajustadas curvas para a \% de germinação cumulativa dos tratamentos ao longo do tempo, adotando-se o modelo $\mathrm{Y}=\mathrm{a} / 1+\left(\mathrm{x} / \mathrm{x}_{0}\right)^{\mathrm{b}}$.

As sementes submetidas à temperatura contínua $\left(20^{\circ} \mathrm{C}\right)$ não germinaram. Nessa condição, nem mesmo os tratamentos de pré-resfriamento mostraram qualquer impacto sobre a germinação da espécie. Contudo, houve germinação nos tratamentos em que a temperatura de pós-resfriamento foi de $20-30^{\circ} \mathrm{C}$. Na prática, essa informação sugere que o nível de infestação da espécie em áreas agrícolas pode estar associado à amplitude térmica.

Foi observado que a temperatura de $10^{\circ} \mathrm{C}$ por um período de 14 dias promoveu maior porcentagem de germinação de $\boldsymbol{L}$. nepetaefolia (tabela 1). Os tratamentos com temperaturas de $5^{\circ} \mathrm{C}$ e $10^{\circ} \mathrm{C}$ durante 14 e 7 dias, respectivamente, não diferiram da testemunha. TOMAZ et al. (2004) não verificaram efeito do pré-resfriamento de $7-10^{\circ} \mathrm{C}$ durante 7 dias na superação de dormência da espécie $L$. nepetaefolia utilizando temperatura pós-resfriamento contínua $\left(20^{\circ} \mathrm{C}\right)$.

Nas curvas de regressão ajustadas para a porcentagem de germinação acumulada no tempo (figura 1), o tratamento $10^{\circ} \mathrm{C}$ (14 dias) foi superior a partir de 5 dias após o estabelecimento das sementes em temperatura definitiva $\left(20-30^{\circ} \mathrm{C}\right)$. $\mathrm{O}$ parâmetro $\mathrm{x}$ da equação, o qual corresponde ao período (dias) em que ocorreu $50 \%$ da germinação indicou 9 dias após a semeadura (DAS) para todos os tratamentos, informação que pode auxiliar no manejo da espécie em áreas agrícolas.

Na tabela 1, pode ser observado que a testemunha apresentou baixa velocidade de germinação comparada ao tratamento pré-resfriado a $10^{\circ} \mathrm{C}$ pelo período de 14 dias. Desse modo, no caso de $\boldsymbol{L}$. nepetaefolia, condições específicas, como quedas de temperatura por determinado período, podem aumentar o IVG da espécie, promovendo germinação antecipada à das culturas, aumentando sua capacidade competitiva.

Na figura 2, podem ser visualizados os fluxos de germinação, a intervalos de 48 horas, dos tratamentos que obtiveram maior porcentagem de germinação e a testemunha, no decorrer das avaliações. Foram necessários cerca de 5 e 7 dias de temperatura alternada para iniciar a germinação das sementes dos tratamentos com e sem pré-resfriamento,

Tabela 1 - Porcentagem de germinação e índice de velocidade de germinação (IVG) de $\boldsymbol{L}$. nepetaefolia em função de tratamentos de pré-resfriamento seguido de temperatura alternada $\left(20^{\circ} \mathrm{C}-30^{\circ} \mathrm{C}\right)$.

\begin{tabular}{lll}
\hline Tratamentos & Germinação $(\%)$ & IVG \\
\hline Testemunha & $29,0 \mathrm{~b}$ & $1,47 \mathrm{c}$ \\
$5^{\circ} \mathrm{C}(7$ dias $)$ & $40,5 \mathrm{ab}$ & $2,10 \mathrm{ab}$ \\
$5^{\circ} \mathrm{C}(14$ dias $)$ & $32,0 \mathrm{~b}$ & $1,66 \mathrm{bc}$ \\
$10^{\circ} \mathrm{C}$ (7 dias) & $29,0 \mathrm{~b}$ & $1,54 \mathrm{bc}$ \\
$10^{\circ} \mathrm{C}(14$ dias $)$ & $45,5 \mathrm{a}$ & $2,49 \mathrm{a}$ \\
\hline
\end{tabular}

Médias seguidas pela mesma letra, não diferem significativamente entre si pelo Teste de Tukey, a 5\% de probabilidade.

Ciência Rural, v.36, n.1, jan-fev, 2006. 


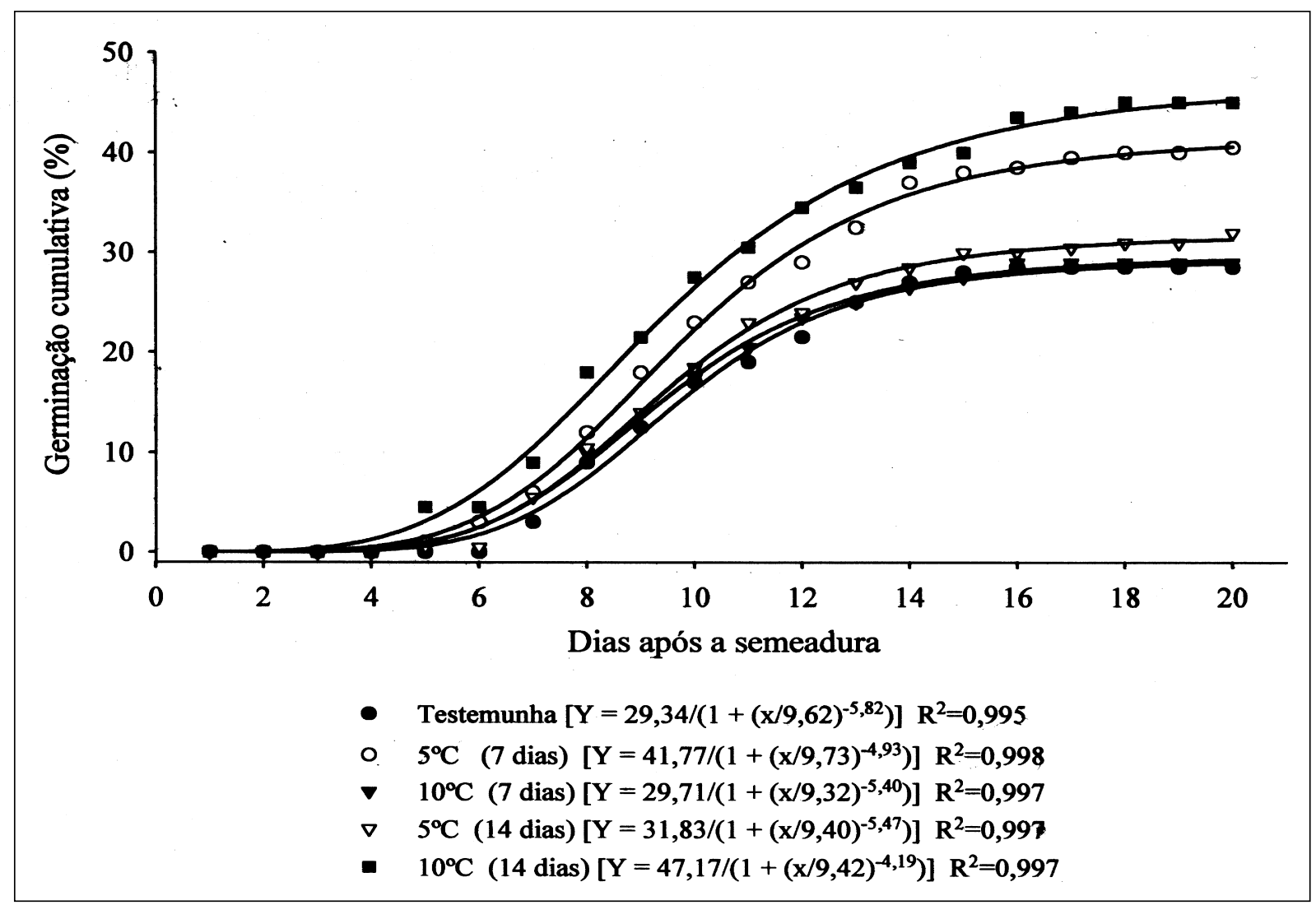

Figura 1 - Germinação cumulativa de L. nepetaefolia ao longo do tempo, em função de tratamentos de pré-resfriamento.

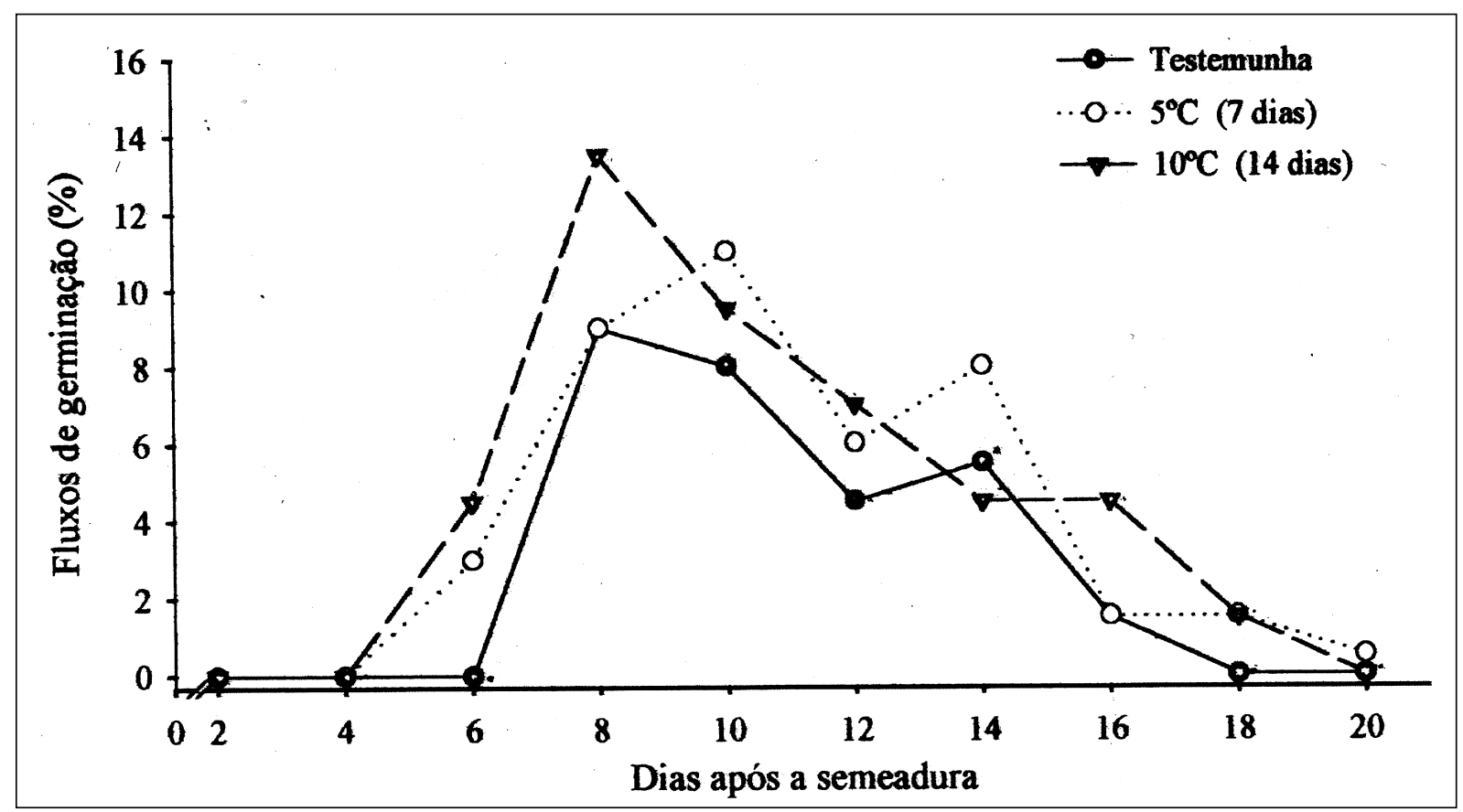

Figura 2 - Fluxos de germinação de sementes de L. nepetaefolia (intervalo de 48 horas), em função de tratamentos de pré-resfriamento.

Ciência Rural, v.36, n.1, jan-fev, 2006. 
respectivamente. O pico máximo de germinação alcançada por $\boldsymbol{L}$. nepetaefolia foi aos 8 DAS para o tratamento $10^{\circ} \mathrm{C}$ (14 dias) e 10 DAS para o tratamento $5^{\circ} \mathrm{C}$ (7 dias). Um aspecto interessante observado no fluxo de germinação foi que o tratamento a $10^{\circ} \mathrm{C}(14$ dias) apresentou maior uniformidade, comparado ao tratamento a $5^{\circ} \mathrm{C}$ (7 dias) que apresentou maiores oscilações. Houve germinação até os 16 DAS para a testemunha, prolongando-se até os 18 e 20 DAS para os tratamentos com pré-resfriamento de $10^{\circ} \mathrm{C}$ (14 dias) e $5^{\circ} \mathrm{C}$ ( 7 dias), respectivamente.

O pré-resfriamento de sementes de $\boldsymbol{L}$. nepetaefolia a $10^{\circ} \mathrm{C}$ por um período de 14 dias, seguido de temperatura alternada $\left(20^{\circ} \mathrm{C}\right.$ noite $-30^{\circ} \mathrm{C}$ dia $)$ promove maior uniformidade, porcentagem e índice de velocidade de germinação em relação à testemunha. A espécie não germina em temperatura contínua de $20^{\circ} \mathrm{C}$.

\section{REFERÊNCIAS}

BRASIL. Ministério da Agricultura e Reforma Agrária. Regras para análise de sementes. Brasília: SNDA / DNDV / CLAV, 1992. 365p

BROWN Jr., K.S. Engenharia ecológica: novas perspectivas de seleção e manejo de plantas medicinais. Acta Amazônica, v. 18 , n.1, p. $291-303,1988$

KISSMANN, K.G.; GROTH, D. Plantas infestantes e nocivas. 2.ed. São Paulo: BASF, 2000. $726 \mathrm{p}$.

LORENZI, H. Plantas daninhas do Brasil. Nova Odessa: Plantarum, 1991. 440p.

MAGUIRE, J.D. Speed of germination-aid in selection and evaluation for seedling emergence and vigor. Crop Sci, v.2, n.2, p.176-177, 1962

TOMAZ, M.A. et al. Germinação de sementes de Leonotis nepetaefolia, em função do estádio de maturação e da posição do glomérulo na planta. Planta Daninha, v.22, n.3, p.359364, 2004. 